\title{
Taking The Student's Lead In Teaching Tax
}

DuWayne Dockter, CPA, USA

\begin{abstract}
Business education, as a discipline and profession, is evolving in response to changes in our domestic and global environment, technology, subject matter content, and needs of the end-user. In response to these changes, business educators continue to evaluate and refine their instructional methodologies and other components of delivery systems within the learning environment. As with courses, such as individual and corporate income tax, instructors for years have relied on the use of published course lecture materials, forms of media, and packaged supplements, such as tax software. The delivery of information in the form of lectures or other conveyances is often followed up by open-ended and short-response questions, but this is only the beginning for one wishing to meet the needs and expectations of employers and students. Seasoned teachers learn to modify the learning environment to meet the learning styles and special needs of their students. The way in which this is accomplished can make the teaching and learning environment exciting and rewarding. This article incorporates ways in which the teacher can build a successful learning environment while meeting the academic goals and objectives of the course.
\end{abstract}

Keywords: individual tax course, tax comprehensive problem, tax instruction, tax instructors, tax learning goals, tax course expectations, tax teaching methodologies, teaching tax, testing strategy, VITA tax program

\section{INTRODUCTION}

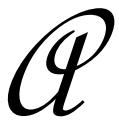

fter years of teaching in the area of business education, you would think that veteran instructors would no longer have to experiment with teaching methodologies; they would have it down pat! However, business education, as a discipline and profession, is evolving in response to changes in our domestic/global business environment, technology, subject matter content, needs of end-users, and other factors.

In response to these changes and demands, business educators continue to evaluate and refine their instructional methodologies and tools of the trade. As a veteran instructor, have I always been successful in applying new teaching approaches? No, but that is why teaching is a learning experience for both teachers and students. Educators grow by experimenting with new teaching approaches that show promise of improving the learning environment.

When I first began teaching tax, I, like most teachers, sought out the advice of seasoned authors on how to best teach a new subject. For me, the instructor's manual was a valuable instructional source to gain this insight. Over time, instructional manuals have evolved and now provide strategies related to key learning objectives, anticipated learning outcomes, time tables for the subject matter to be covered, lecture notes, PowerPoint presentation slides, exercise and problem answer keys, margin notes, and a host of other references. The incorporation of specific teaching tools, such as tax software, has also been a bonus provided by the publishers.

Of course, one of the biggest obstacles for teachers is the lack of time to incorporate their own innovations and instructional recommendations, no matter their source. However, it is up to the instructor to choose which teaching methodologies and tools best fit the course and benefit the students the most given this time constraint.

\section{SO WHERE DOES ONE BEGIN?}

For the novice teacher, the instructor's manual was and is a good place to start. As stated earlier, it provides teachers with the structure, content, and tools to build a rewarding learning environment. This is especially true when teaching introductory courses, such as individual or corporate income tax, for the first time. 
As in the past, students still need to learn the conceptual framework of tax law and its applications. Of course, there have been many refinements over the years in how the materials are presented, learning is evaluated, and software used to enhance and reinforce the learning process. Of course, the student's job has been made more convenient with the use of on-line tax research and educational support tools. It is a far cry from the way in which individuals in the past had to search for references in a paper system.

Tax textbooks have also evolved with time; they have become more user-friendly in response to the needs of students and teachers. Today, the textbooks are a better learning tool, not only in terms of readability, but imbedded references connected to on-line or DVD databases.

In order to improve the course materials, delivery systems, and integrated software packages, authors and publishers are constantly surveying instructors on what needs to be added, refined, or dropped. Students are also being surveyed for their opinions when using on-line reference tools and software packages. As a result of the inputs, the products and delivery systems have improved.

\section{GUIDANCE IN TEACHING TAX}

If one follows the suggested sequence as outlined in most instructional manuals, the instructor will use a lecture methodology interlaced and/or follow-up with a variety of open-ended, short-response conceptual-based questions. Next, the teacher would assign and discuss short-exercises and/or problems which will test the students' understanding of what was covered. As the course progresses, the teacher would also require students to do tax research. This would help them grasp an understanding on how different authorities interpret tax law and how it is applied in the real world of tax. At the end of each learning unit, the teacher would assign and discuss a series of cumulative and comprehensive problems.

As a final step, there are the evaluation tools that the teachers use to gauge the students' understanding of what has been taught. But what about the expectations of other interested parties to the learning process?

\section{COURSE EXPECTATIONS}

Teachers, students, and other stakeholders, such as employers, have expectations that also need to be satisfied. These expectations include a basic understanding of tax law and its applications. This is a basic requirement for any course and will quickly be put to the test in the field. In order to meet these expectations, teachers use a combination of instructional methodologies and tools to guide the learning process. As a result, most of our accounting students today are well equipped to enter the workplace and they have a basic understanding of tax law and how it can be applied. But what other factors must be considered?

\section{SURVEYING THE STUDENTS}

Students come into a class with many expectations and experiences that are valuable inputs to the learning process. This is why a survey of the student's educational and work experience background is essential. Not only does it provide for a good ice-breaker in knowing one's students, but the students' experiences are a constant source of information that can be related to the subject matter, whether it touches on the subject of business ethics or work practices followed in the field of accounting. It also allows the students an avenue in which to add to on-going classroom discussions. This is especially true when working with non-traditional students who have already gained a wealth of knowledge and experiences that are from or related to the area of study.

\section{LEARNING STYLES DIFFER}

Recognizing and evaluating how students learn helps to build a beneficial and supportive learning environment using different teaching tools and methodologies.

For instance, the combination of a chapter presentation tool, such as PowerPoint slides and a pre-chapter overview of principal concepts to be emphasized, helps students to direct their chapter reading. The discussion of open- 
ended questions and problems also helps to instruct and gauge the students' understanding of those concepts. But as with any group of learners who are unique, the teaching methods must and do often need to be modified. As an old colleague once told me, we need to satisfy the customers (students) in terms of their needs.

As an example, the use of short and more cumulative problems helps to illustrate how tax concepts and tax laws are applied in the field. Once the conceptual foundation has been laid and applied using a series of short questions and problems, students can further reinforce their understanding of the tax law and how it is interpreted by different authorities using appropriate on-line research tools. This on-going research by the students, with the guidance of their instructors, helps to diversify the learning environment and reinforce what has been taught and what needs to be learned. But what is great about this type of approach is that it is student-driven, therefore satisfying the needs of the students and end-users, such as employers. In evaluating how students learn, we must also pay attention to students with special needs who do not respond to the norm in terms of teaching approaches.

\section{STUDENTS WITH SPECIAL NEEDS}

The way in which a subject is presented, and the physical learning environment, may also need to be modified for those students with special needs. The modifications come from different sources. Among them, surveying students on an individual and on-going basis is important. Building a good learning environment that meets everyone's needs also includes receiving input from counselors and significant others.

As veteran teachers have discovered, students with special learning disabilities and challenges are not always forefront with this information. It is often considered by them as a very private and personal challenge. So, teachers must be alert to warning signs observed in class. Often, teachers learn of a problem after the fact, whether it is something simple as history of testing anxiety displayed during testing or a student who has been diagnosed as being bi-polar and not able to concentrate in class. So, no matter what the obstacle to learning, the learning environment may need to be modified.

\section{LECTURES AND INQUIRY APPROACHES TO LEARNING TAX}

Innovative and creative teachers are always interested in learning new approaches or refining their existing approaches to improve the classroom learning environment. Teaching tax is no exception.

When I first began teaching tax, I, like most teachers, looked to the publishers' manuals for guidance. In the old days, lectures were one of the principal presentation methods utilized by teachers to convey important information to the students. These chapter outlines are still available in instructor manuals supplemented with helpful suggestions, chapter sections to be emphasized, PowerPoint presentation slides, and other forms of media presentation tools. There is no doubt that if used in conjunction with other teaching methodologies, lectures are still a good presentation delivery system. When the lecture method is mixed with other methodologies, such as the inquiry approach, it allows students more opportunities to interact with the teacher. The resultant on-going dialogue adds much to the learning process. Also the use of open-ended questions enable students to be better examiners in the field when trying to discover the source of and reasons for certain accounting transactions.

For my students, an in-class lecture was not the best method. Students wanted more in-class time devoted to practice problems. In hind site, it was the best method to help students understand tax concepts, laws, and its applications.

After discussing the goals of the class and different approaches with the students, we tried an approach incorporating a mixture of different methodologies, as outlined below, but the first step was to put less emphasis on the use of lectures after the first introductory chapters.

As an alternative with the specific application chapters, abbreviated chapter outlines with the teachers' embedded notes were posted on a class website in addition to the publishers' PowerPoint presentation slides. However, I did not want these materials to be used as a casual reference, so students were strongly encouraged to use them as a study 
tool and they were shown how the on-line lecture notes could be used as a study tool. That doesn't mean that we didn't ever use the PowerPoint slides in class. In fact, students who were asked to make a presentation of selected, advanced chapters (e.g., trusts and estates) often used the author's or their own PowerPoint presentation slides as a discussion vehicle and learning tool.

For each of the chapters dealing with the specific application of the tax law, a chapter overview by the instructor was completed before the students read the chapter in detail. This planning tool helped the students focus on major concepts and pertinent tax laws dealing with each chapter. As mentioned earlier, the teacher and students chose to spend the majority of class time reviewing assigned questions and working on illustrative problems similar to the ones assigned to the students. The students were also appreciative that they were made part of the planning process.

This approach was also helpful when reviewing chapters where students were assigned cumulative tax problems for the first time. Completing the first comprehensive and cumulative problems as a group was/is a big plus for the students. It helped them to build self-confidence and understand the flow of information necessary for the proper preparation of tax forms. However, students must also be encouraged to show self-initiative, so hand-holding must be kept to a minimum. Real world practitioners would expect no less from our graduates.

\section{USING MANUAL TAX FORMS}

As with many veteran teachers, students would use paper forms to complete problems from the first application chapters. At least one demonstration problem would be completed in class. They could be completed on an old fashioned overhead or projected electronically. It gave the class an excellent opportunity to discuss the important and relevant facts that needed to be identified in the problem. As the students identified and gathered the relevant information and learned how, why, and where to place it on the forms, we discussed how the information flowed from one form or schedule to the next. This manual review process was time consuming but laid an important foundation for later preparing returns electronically. As most tax instructors realize who have worked in the field, it is essential that students understand how the information inputted into a tax software program is processed. This process is crucial when reviewing one's own return or others, making sure that the computer is processing the data accurately and that the user is inputting the information properly. In the work place, there is a low tolerance for mistakes when it comes to preparing returns for the end-user. As the old expression states, time is money. Managers don't want a lot of redoes and depend on seasoned preparers to produce a finished product with no mistakes.

\section{COMPUTERIZED TAX FORMS}

Once the students had mastered the use of the tax forms, they were introduced to a tax software program. Most manufacturers will supply a restricted version to educational institutions at a reduced rate or no cost; otherwise, the publisher may have supplied a tax program along with the textbook. Since the students would be using similar commercial tax programs in the field, the extra time or cost to obtain the full version of the tax program is well worth the effort.

As an alternative, instructors could ask the Internal Revenue Service to enroll their students in a VITA-type program. The IRS and associations, such AARP who utilize tax preparation volunteers throughout the United States, are usually happy to supply the training materials and software programs. Of course, if the materials are supplied by one of these groups or agencies, there is usually a hitch. Your students may be expected to volunteer time to help taxpayers prepare their returns; however, it does provide students with practical experience and an opportunity to provide community service.

With respect to the VITA program, the logistics of when students will be trained or how they will be granted credit will need to be worked out with the faculty and administration. Fortunately, most schools are now very receptive to providing this type of community support.

In many schools, the introductory income tax course is taught in the fall. This provides instructors with a good opportunity to train students in preparing returns according to the guidelines set by support agency or association. If time 
is not allowed during the individual tax course to train student volunteers, a separate mini-course or series of seminars can be offered. This second option also provides non-accounting majors and students not enrolled in a tax course to participate. This is common when students on campus want to learn more about preparing their own taxes as an example. Of course, some students will need or wish to provide community service as part of their graduation requirements. Accounting clubs on campus can also provide an incentive for individuals to participate. No matter the reason, there are a lot of mutual benefits to the school, students, and community.

\section{EVALUATING STUDENTS ALONG THE WAY}

Every teacher has devised many ways in which to evaluate the students' learning progress and appropriate timing of each, and of course, the publishers have been very instrumental in making evaluation instruments available and convenient. With few exceptions, most authors/publishers provide the instructors with paper and electronic test banks; all the teacher has to do is select or randomly choose suitable questions.

Over the years, most teachers learn quickly that the authors' test bank needs to be modified to meet what has been taught/emphasized in the class and the special needs/circumstances of the students.

Most teachers choose an assortment of multiple choice questions, open-ended questions, short exercises, problems, and essays to gauge the students' conceptual knowledge of the subject matter, communication skills, and application skills. Teachers also want to evaluate the students' progress during the semester, whether using a traditional approach or teaching a class online. Of course, there are many teachers who have built their own test banks over the years from an assortment of sources, whether it be items from publishers' test banks, CPA question test banks, or sources.

There is also the question on how often to evaluate the students. Most teachers learn quickly that if left up to the students, they don't want to be tested at all. However, that is not an acceptable alternative for the teacher in light of providing the employers with some bench marks for comparing the student's success compared to others. However, a project developed by the student at the culmination of the class is a viable option that will be discussed in greater length later.

No matter the evaluation tool, the teacher must select the best instrument that best gauges the student's progress and evaluates to what degree the teaching/learning objectives of the class have been accomplished. In most classes, including my own, teachers administer a series of chapter quizzes and then a unit test. In this way, students will have more than one opportunity to prove themselves and demonstrate that they have learned from their mistakes.

Going one step beyond, in respect to a testing strategy and a means by which test anxiety is reduced, some teachers are now administering practice and group quizzes to their students. This strategy gives students an opportunity to test themselves while the teacher and student learn what they do and don't know. It is very much like the first initial audit or tax return prepared in the field and reviewed by the next in command. The employees, or in our case, students, learn from their mistakes. Providing students with a way in which something will be tested often leads to reduced test anxiety. When it comes to the follow-up and individual quizzes and unit tests, we will be more likely to test what a student knows.

Earlier, we spoke of assigning culminating projects as a valuable evaluation tool. A good example is one in which students complete or create a comprehensive problem for an individual or corporate tax course.

In the individual tax course, we stated earlier that students often work initially with the teacher in completing short cases. In doing so, the students are able to build the necessary skill set and knowledge base to complete more comprehensive problems using manually-prepared and computer-generated tax returns. At the end of the class, instead of administering a question-driven final, the teacher can also require students to complete a comprehensive problem. The problem can be done as a class project during the last week and submitted on the day of the final. It makes for a challenging examination and an additional portfolio item for the students to show their future employers. 
In the more advanced classes, such as corporate income tax, the teacher can challenge the students even more. How? The teacher can ask the students to produce their own comprehensive problem, similar to ones completed in class, given certain minimum requirements. Students in my classes have met the challenge well by presenting the facts in a very professional and logical manner. Of course, not excluding the students' sense of imagination and humor. Of course, the students had to supply their instructor with written summary of the case and answer key in the form of prepared tax forms. In the process of preparing an answer key for the comprehensive problem, it helped students to detect necessary facts that were omitted from the students' fact sheet. In essence, it taught the students the importance of conducting a good interview and necessity of follow-up conversation with a tax client to complete the return. It also emphasized the importance of good proofreading if the facts did not correlate fully with the prepared return. In all, it is a good way to evaluate the students.

\section{CONCLUSION}

Among all the courses I have taught in accounting, tax has been one of the most rewarding. First, students who take the course usually have a higher interest level in this course because of its immediate rewards. The hands-on activities related to the course also make it fun and help the student relate better to the course materials. It is also a fun course for the teacher because there are so many ways in which the course can be taught.

At the end of the introductory course, students should be able to prepare taxes for themselves, friends, and family members. Of course, the skill is valuable as an entry-level point in many public accounting firms. For example, students can obtain an internship with a public accounting firm during the tax season. In turn, this experience gives them a better footing in securing a full-time job with their current employers or improves their chances with another employer.

\section{AUTHOR INFORMATION}

Dr. DuWayne Dockter CPA has taught on the secondary and post-secondary levels for over 30 years. Formerly, Dr. Dockter was a full professor of accounting at Concordia University and has worked as an IRS revenue agent, consulted in the area of taxation, and worked for a local and an intermediate public accounting firm. Recently, the author gained additional experience working for a local CPA firm working on Partnership and Corporate tax returns.

\section{REFERENCES}

1. Bender, William. Differentiating Instruction for Students with Learning Disabilities: Best Teaching Practices for General and Special Educators. $2^{\text {nd }}$ ed. Thousand Oaks, CA: Corwin Press, 2008. Print.

2. Joyce, Bruce, and Marsha Weil. Models of Teaching. $8^{\text {th }}$ ed. Upper Saddle River, NJ: Allyn and Bacon, 2009. Print.

3. Hoffman, William, William Raabe, and James Smith. 2010 Corporations, Partnerships, Estates and Trusts. Mason, OH: Thomson South-Western, 2010. Print.

4. Hoffman, William, William Raabe, and James Smith. 2010 Individual Income Taxes. Mason, OH: Thomson South-Western, 2010. Print.

5. Rosenburg, Marc. e-Learning: Strategies for Delivering Knowledge in the Digital Age. New York: McGraw-Hill, 2001. Print.

6. Sanders, Norris. Classroom Questions: What Kinds? New York: Harper and Row, 1966. Print 